\title{
DEVELOPMENT OF A NEW DRAG COEFFICIENT MODEL FOR OIL AND GAS MULTIPHASE FLUID SYSTEMS
}

\author{
K. O. Bello ${ }^{1}$ and K. I. Idigbe ${ }^{2}$ \\ 1, 2 Department of Petroleum EngineERING, University of Benin, Benin City, NigERIA \\ Email addresses:1belloko@uniben.edu, ${ }^{2}$ kiidigbe@gmail.com
}

\begin{abstract}
Multiphase flows involving suspensions of solid particles are frequently encountered in many industrial processes including oil \& gas production. In order to transport solid entrained multiphase fluids, especially through a pipeline, the fluids must be capable of suspending the entrained solid particles to prevent solid deposition and flow assurance challenges. The particle drag coefficient, $C_{D}$, is a key hydrodynamic parameter, and its effective determination is critical to ensuring effective transportation of the particles. In this work, the results of laboratory measurements of the terminal settling velocity of sand particle(s) in multiphase fluids are presented. The results allow the proper determination of the particle(s) Reynolds number, $C_{D}$. The developed $C_{D}$ model is an improvement on existing models, which can be applied to both the turbulent and laminar flow regions, thus, reasonably predicting $C_{D}$ over a wide range of $R_{e p}$ in multiphase fluid flow. It effectively accounts for the complexities associated with multiphase flow in pipes, and has the potential to solve the problem of sand depositions, and thus, minimizing flow assurance challenges in multiphase flow.
\end{abstract}

\section{INTRODUCTION}

Multiphase flow involving suspensions of solid particles are frequently encountered in many industrial processes including oil \& gas production. The ability of fluids in horizontal motion to suspend solid particles depends on the balance of two actions: gravity, which causes the particles to fall or settle in the fluid, and an upward diffusion of the particles, caused by a concentration gradient of particles which in turn is created by gravity $[1,2]$. The particle movement thus, depends on the properties of the solids such as solids density, particle size and particle shape. The gravitational force causing the particle to rise or fall can be defined as [1]:

$$
F_{g}=\frac{\pi d^{3}}{6}\left(\rho_{p}-\rho_{f}\right) g
$$

The rise or fall of the particles in the fluid results in a lift \& drag force where this force may be expressed as:

$$
F_{D}=C_{D} \frac{\rho v^{2}}{2} \frac{\pi d^{2}}{4}
$$

In (2), $\rho_{p}$ is the particle density, $\rho_{f}$ is the fluid density, $\mathrm{d}$ is the particle diameter, $\mathrm{m}, \mathrm{g}$ is the coefficient of gravity, $C_{D}$ is the drag coefficient and $v$ is the rise or fall velocity, $\mathrm{m} / \mathrm{s}$. The drag force arises from pressure and viscous stresses applied to the particle surface and resist the relative fluid velocity $\mathrm{v}$ [3]. The magnitude of drag is primarily dictated by the particle's Reynolds number, $\mathrm{R}_{\mathrm{ep}}$, defined as:

$$
R_{e p}=\frac{\rho_{f} v_{f} d_{p}}{\mu_{f}}
$$

In (3), $v_{f}$ is the fluid velocity $(\mathrm{m} / \mathrm{s}), \mathrm{d}_{\mathrm{p}}$ is the particle diameter (m) and $\mu_{f}$ is the fluid viscosity (cp). The particle drag coefficient is a very important hydrodynamic parameter involved in the modelling and design of multiphase processes especially when entrained with solid particles. From a hydrodynamic viewpoint, the fundamental aspects of solid-liquid multiphase flow are inter-phase interaction (i.e., interaction between the fluid phase and the particulate phase) and intra-phase interaction (i.e., interaction among solid particles making up the particulate phase). Inter-phase interaction between the fluid phase and the particulate phase is manifested mainly in the drag force exerted on the particles by the fluid stream and the transfer of momentum from one phase to another [4]. Several correlations for drag coefficient have been proposed over a wide range of Reynolds number in the literature. One of the most 
widely used is the empirical equation of Schiller and Neumann, which is simple and effective in the range $0.1<\operatorname{Re}<800$ [5], expressed as:

$$
C_{D}=\frac{24}{R_{e}}\left(1+0.15 R_{e}^{0.687}\right)
$$

Cheng 2009 [6], proposed a drag coefficient model which has greater applicability when compared with other models evaluated. These other models can only be used for limited Reynolds numbers and even those applicable for wider range of $R_{e}$, may involve tedious application procedure. The model proposed by Cheng [6] given below, despite its simple form, gives the best approximation of experimental data for $R_{e}$, from Stoke's regime to about $2 \times 10^{5}$.

$$
C_{D}=\frac{24}{R_{e}}\left(1+0.27 R_{e}\right)^{0.43}+0.47\left[1-\exp \left(-0.04 R_{e}^{0.38}\right)\right]
$$

This drag coefficient $C_{D}$ is predicted from two terms. The first term on the RHS can be considered as an extended Stokes' law, applicable approximately for $\mathrm{R}_{\mathrm{e}}$ $<100$; and the second term is an exponential function accounting for slight deviations from the Newton's law for high $\mathrm{R}_{\mathrm{e}}$. The sum of the two terms is used to predict drag coefficient for any $\mathrm{R}_{\mathrm{e}}$ over the entire regime. Available drag correlations in the literature apply to smooth spherical particles, or regularly shaped particles like disks or cylinders. But particles encountered in the oil and gas production usually are not smooth spheres but are irregularly shaped and do not have smooth surfaces [7]. In fact, there is remarkable difference between spherical and nonspherical particles in the context of the method in which they tend to commence motion, given that spherical particles tend to begin motion via rolling whereas non-spherical particles preferably commence motion via dragging [8]. Another drawback is that the correlations were developed from solids transport situations where the solids loading is very high. Typical sand loading in offshore applications is much smaller than most industrial solid-liquid slurry transport, on the order of 5-40 lb of sand per $1000 \mathrm{bbl}$ of produced liquid [9].

For the case of flow around a sphere, certain hydraulic analyses require determining the drag coefficient as well as lift coefficient as a function of particle Reynolds number. This is true for the present study, in the determination of minimum transport velocity models for suspension and rolling. A key parameter is the particle settling velocity within the multiphase flow in pipeline. One challenge is that the drag coefficient cannot be expressed in an analytical form for a wide range of particle Reynolds numbers, because the flow condition during the process is highly complicated [10]. Even with the advent of CFD, performing large scale numerical study of complex multiphase flow requires some assumptions and also empirical data describing the interactions between the fluid and the particles [11]. This relationship can generally be determined experimentally by observing the settling velocities in still fluids $[10,12]$.

\section{METHODOLOGY FOR DEVELOPMENT OF DRAG COEFFICIENT $\left(C_{D}\right)$ CORRELATION}

The definition of the drag force on a particle in a fluid flow generally involves the understanding of the relationship between the drag coefficient $C_{D}$ and particle's Reynolds number, $\mathrm{R}_{\mathrm{ep}}$. The drag coefficient represents the fraction of the kinetic energy of the settling velocity that is used to overcome the drag force on the particle, while the Reynolds number is a ratio between the inertial and viscous forces of a fluid [13]. As the particle size or flow velocity increases for a given kinematic viscosity, so does the Reynolds number, and the character of flow changes as expressed in Equation 6. For very small Reynolds numbers, Stokes proposed an analytical solution of drag coefficient by solving the general differential equation of Navier-Stokes.

$$
C_{D}=\frac{24}{\operatorname{Re}}
$$

An analytical attempt to extend the range of approximation for the drag coefficient beyond Stokes flow was proposed by some authors by including the inertia terms in the solution of Navier-Stokes as reported by [10].

$$
C_{D}=\frac{24}{\operatorname{Re}}\left(1+\frac{3}{36} \operatorname{Re}\right)
$$

A number of empirical and semi empirical $C_{D}-R_{e}$ relationships, can be found in the literature $[14,10]$. Four of the $C_{D}$ correlations $[15,6]$ are shown below for comparisons because they are generally considered to be of high accuracy and with wide range of applicability; equations 8 to 11 .

$$
\begin{aligned}
C_{D} & =\left[\left(\frac{24}{\operatorname{Re}}\right)\left(1+\left(0.173 \mathrm{Re}^{0.657}\right)\right)+\left(\frac{0.413}{1+16300 \mathrm{Re}^{-1.09}}\right)\right] \\
C_{D} & =\left[0.5\left(\frac{24}{\operatorname{Re}}\right)^{1.6}+\left(\left(\frac{130}{\operatorname{Re}}\right)^{0.72}\right)^{2.5}+\left(\left(\left(\frac{40000}{\mathrm{Re}}\right)^{2}+1\right)^{-0.25}\right)^{0.25}\right] \\
C_{D} & =\left[\left(\frac{24}{\operatorname{Re}}\right)(1+0.27 \mathrm{Re})^{0.43}+0.47\left(1-\exp \left(-0.04 \mathrm{Re}^{0.38}\right)\right)\right]
\end{aligned}
$$




$$
C_{D}=\left[\left(\frac{24}{\operatorname{Re}}\right)\left(1+\left(0.15 \operatorname{Re}^{0.687}\right)\right)\right]
$$

\section{EXPERIMENTAL SET UP}

An experimental determination of the drag coefficient is often based on measurement of the terminal settling velocity of a sand particle in fluid medium. In the present study, data from experiments conducted for particle settling velocity has been used to determine the $R_{\text {ep }} \& C_{D}$ relationship, see Table 1 . The deposit velocity for solid-liquid mixture is the velocity below which solid particles will settle out of slurry to form a moving bed or a stationary bed. The deposit velocity was determined experimentally both at static and dynamic conditions in order to evaluate the drag and lift coefficients. An experimental set-up was designed and constructed; see the Digital picture of the vertical test column in Figure 1.

In order to determine deposit velocity in static condition, the vertical pipe column was filled with test fluid. The particle sample was dropped from the top of the vertical tube and observed as it travelled through the liquid column. On the side of the column are marked different points. The time taken for the particle to travel from the top to different level or distant from the top was noted and recorded with the aid of stop watch. This procedure was repeated three times for each sample particle for single phase water, oil and two-phase oil-water, oil-gas, water-gas and for three phase oil-water-gas. In each case gas flow rates were varied and settling velocity observed at different gas flow rates.

Schiller Neumann $C_{D}$ correlation is commonly used as drag correction expression in multiphase flows since many particles are constrained to $R_{\text {ep }}$ values in this range. However, it was observed that the main limitation of the model was its limited capability for predicting the laminar flow region. The model was then modified especially to improve on this limitation. This led to the development of a new $C_{D}$ correlation based on the experimental data for multiphase, wateroil-gas flow see Table 1 . The development of the new $\mathrm{C}_{\mathrm{D}}$ correlation that is a function of Reynolds number was based on fitting the newly acquired experimental data to the base equation using MS-Excel program. The generic form of the equation is described as:

$$
C_{D}=\left[\left(\frac{24}{\operatorname{Re}}\right)\left(1+\left(0.15 \operatorname{Re}^{0.687}\right)\right)+\left(\frac{a}{\left(b+c \operatorname{Re}^{d}\right)}\right)\right]
$$

In (12) $R_{e}$ is the particle Reynolds number and a, b, c and $d$ are constants dependent on experimental data.

\begin{tabular}{|c|c|c|c|c|}
\hline \multicolumn{5}{|c|}{ Single-Phase Oil Flow } \\
\hline $\begin{array}{l}\text { Particle } \\
\text { Den }\end{array}$ & $\begin{array}{c}\text { Particle } \\
\text { Size }\end{array}$ & $\begin{array}{c}\text { Velocity, } \\
\mathrm{m} / \mathrm{s}\end{array}$ & Rep & $\mathrm{CD}$ \\
\hline 1066.67 & 0.01127 & 0.186 & 2.9 & 14.12926 \\
\hline 1034.48 & 0.01035 & 0.039 & 0.42 & 73.2703 \\
\hline 1038.96 & 0.01302 & 0.126 & 1.72 & 18.22477 \\
\hline 1052.63 & 0.00899 & 0.034 & 0.32 & 96.16358 \\
\hline 1090.91 & 0.01281 & 0.242 & 3.24 & 10.51653 \\
\hline 1250.00 & 0.01152 & 0.017 & 0.2 & 149.7766 \\
\hline 1100.00 & 0.01563 & 0.057 & 0.93 & 33.79908 \\
\hline \multicolumn{5}{|c|}{ Two-Phase Oil-Air Flow } \\
\hline 1066.67 & 0.01127 & 0.332079 & 343.28 & 0.532202 \\
\hline 1034.48 & 0.01035 & 0.095532 & 90.65 & 1.899549 \\
\hline 1038.96 & 0.01302 & 0.150241 & 179.35 & 0.943582 \\
\hline 1052.63 & 0.00899 & 0.107232 & 88.37 & 1.296264 \\
\hline 1090.91 & 0.01281 & 0.333204 & 391.35 & 1.325062 \\
\hline 1250.00 & 0.01152 & 0.16388 & 173.09 & 0.811856 \\
\hline 1100.00 & 0.01563 & 0.121378 & 174 & 1.587986 \\
\hline \multicolumn{5}{|c|}{ Two-Phase Oil-Water } \\
\hline 1066.67 & 0.01127 & 0.186 & 2.19 & 14.12926 \\
\hline 1034.48 & 0.01035 & 0.039 & 0.42 & 73.2703 \\
\hline 1038.96 & 0.01302 & 0.126 & 1.72 & 18.22477 \\
\hline 1052.63 & 0.00899 & 0.034 & 0.32 & 96.16358 \\
\hline 1090.91 & 0.01281 & 0.242 & 3.24 & 10.51653 \\
\hline 1250.00 & 0.01152 & 0.017 & 0.2 & 149.7766 \\
\hline 1100.00 & 0.01563 & 0.057 & 0.93 & 33.79908 \\
\hline \multicolumn{5}{|c|}{ Three-Phase Oil-Water-Air } \\
\hline 1066.67 & 0.01127 & 0.225128 & 6.28 & 5.219091 \\
\hline 1034.48 & 0.01035 & 0.116084 & 2.97 & 11.65592 \\
\hline 1038.96 & 0.01302 & 0.119877 & 3.86 & 8.540476 \\
\hline 1052.63 & 0.00899 & 0.099228 & 2.21 & 14.54396 \\
\hline 1090.91 & 0.01281 & 0.232556 & 7.37 & 5.316265 \\
\hline 1250.00 & 0.01152 & 0.095857 & 2.73 & 11.61268 \\
\hline 1100.00 & 0.01563 & 0.174339 & 6.75 & 5.861403 \\
\hline
\end{tabular}

Table 1: Sand deposit experimental results for CD models

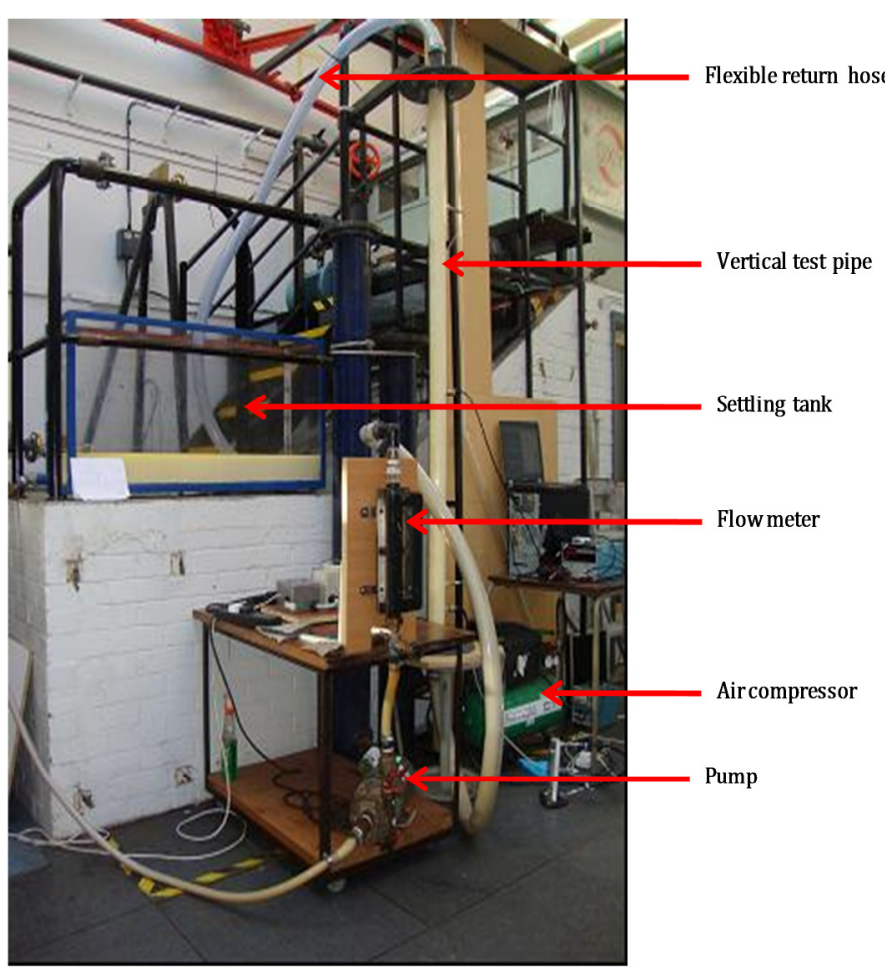

Figure 1: Digital picture of the vertical test column 


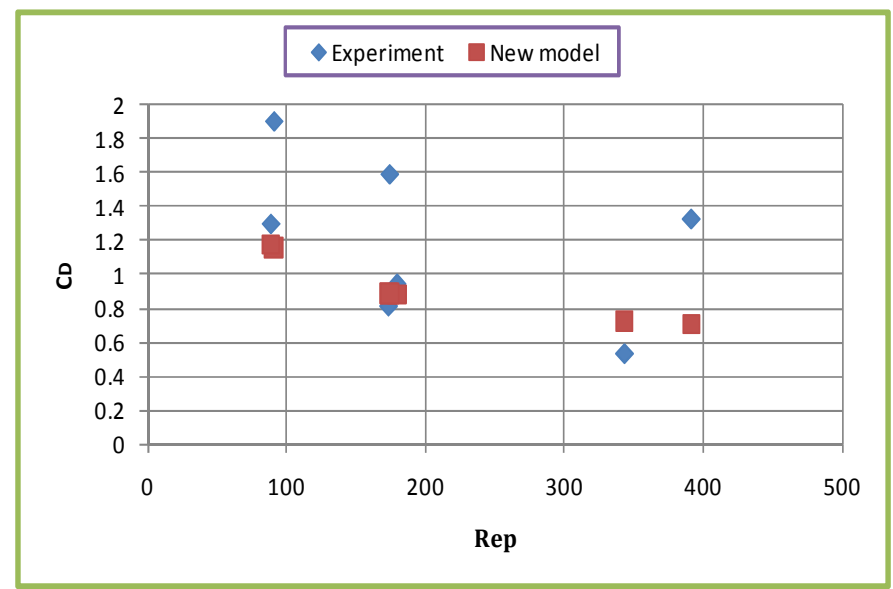

Figure 2: $C_{D}-R_{e p}$ for two phase oil-gas flow

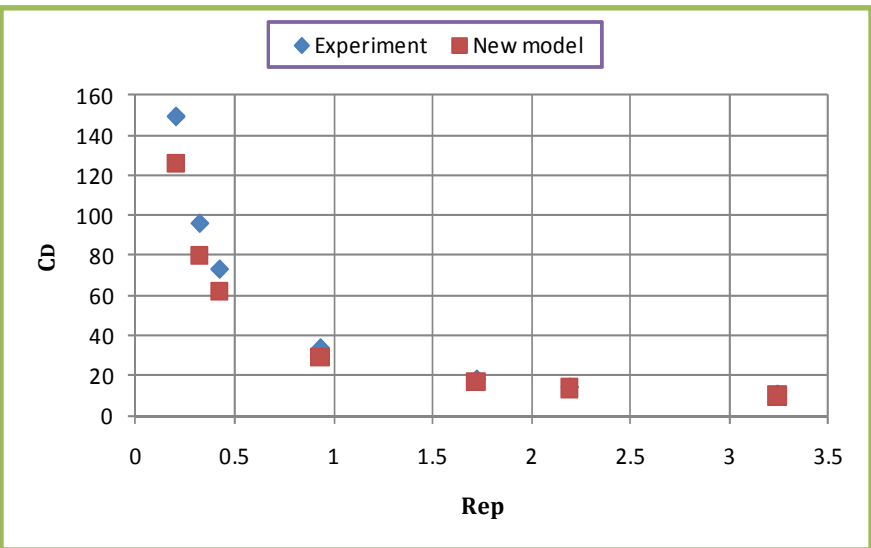

Figure 4: $C_{D}-R_{e p}$ for two phase oil-water flow

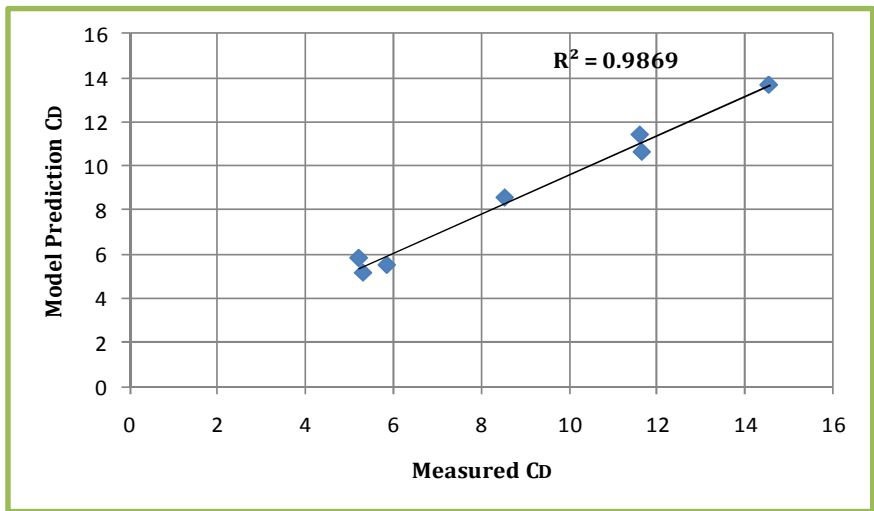

Figure 6: Comparison of measured and model prediction $C_{D}$ for water-oil-air flow

Solving for these unknowns, the equation that best fits the experimental data was determined and can be expressed as:

$$
C_{D}=\left[\left(\frac{24}{\operatorname{Re}}\right)\left(1+\left(0.15 \operatorname{Re}^{0.687}\right)\right)+\left(\frac{3.5}{\left(1+42500 \operatorname{Re}^{-1.17}\right)}\right)\right]
$$

The experimental data was divided into three parts; one part was used mainly for model development, the second sets of data were used for model testing and the third sets of data were dedicated to model validation. In total, seven different glass bead samples were used during the experiments. The predictions

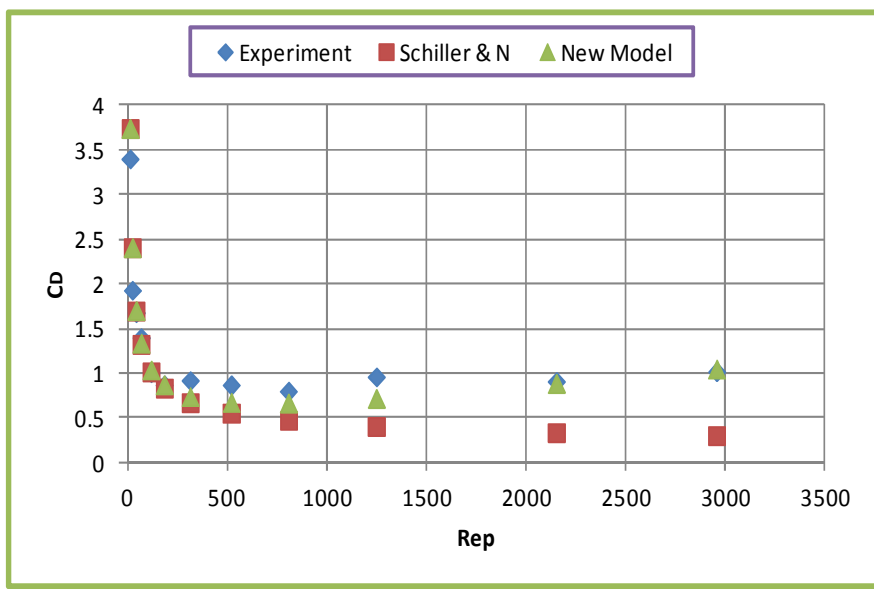

Figure 3: $C_{D}-R_{e p}$ for single phase water showing improved correlation with new model

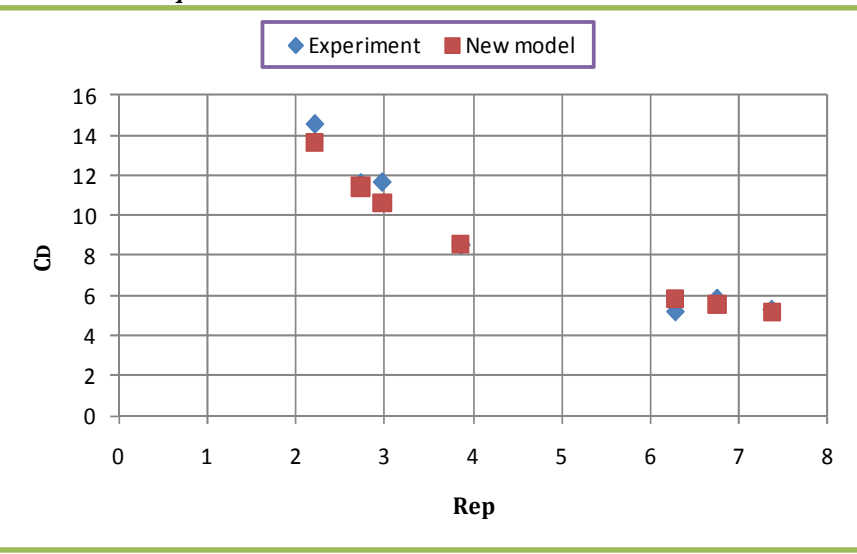

Figure 5: $C_{D}-R_{e p}$ for three phase oil-water-gas flow

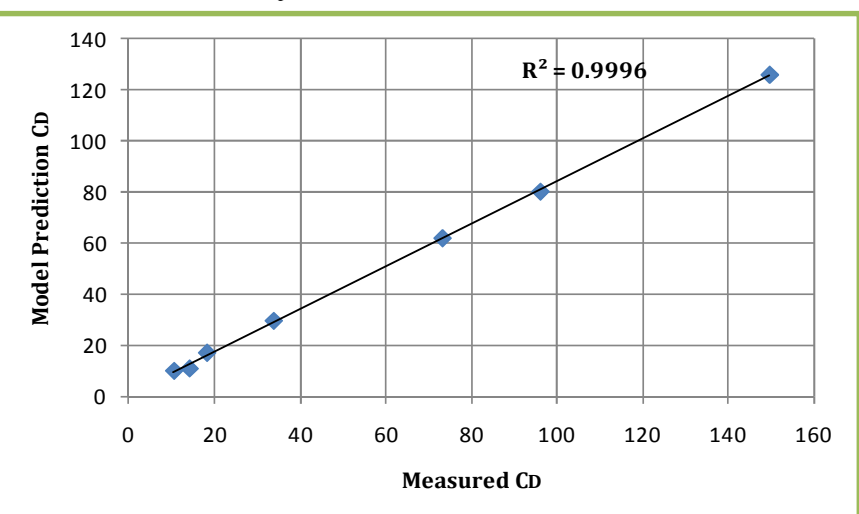

Figure 7: Comparison of measured and model prediction $C_{D}$ for single-phase oil flow

with the model match the measurements quite well. Only a minor deviation was observed as can be seen in Figure 2 with oil-gas experiment. The RSQ correlation coefficient was $79 \%$.

The developed $C_{D}$ model was an improvement on Schiller Neumann model, see Figure 3. It incorporated an extended Stokes law and the deviations from the Newton's law. This can be applied to both the turbulent and laminar flow regions and reasonably predict $C_{D}$ over a wide range of $R_{e}$ in multiphase fluid flow. 


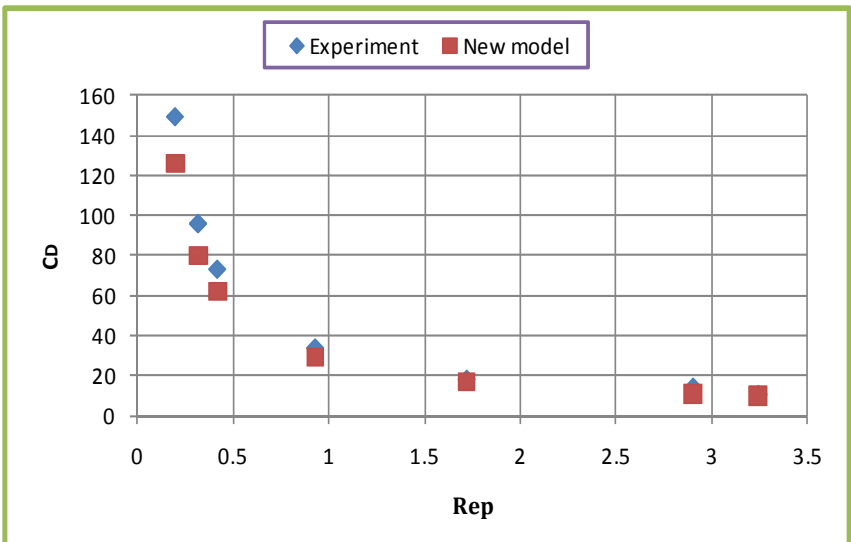

Figure 8: $C_{D}-R_{e p}$ for single phase oil flow

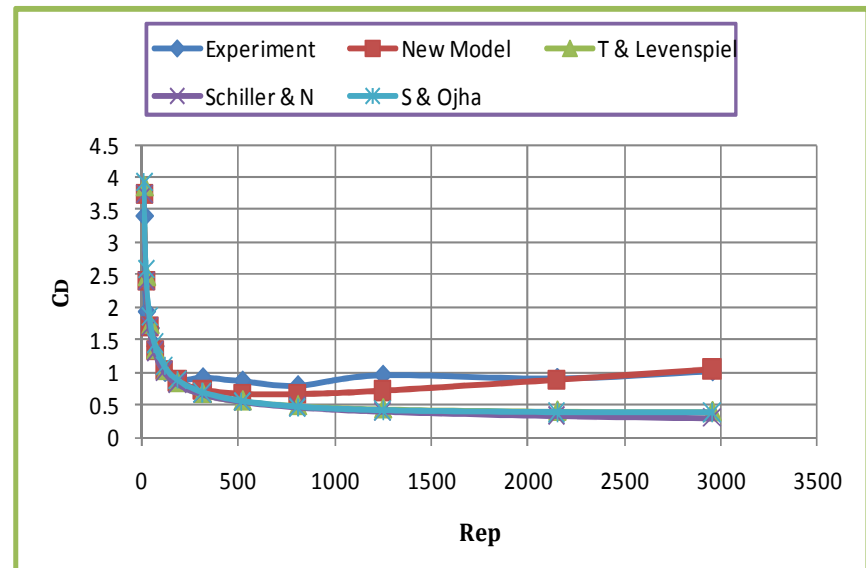

Figure 10: New $C_{D}$ model compared with selected models from literature

\section{NEW DRAG COEFFICIENT $\left(C_{D}\right)$ MODEL: TESTING, VALIDATION AND COMPARISON}

In order to establish the reliability and accuracy of the new model, it was tested with other sets of data. The results for two-phase oil-water flow and three-phase oil-water-gas flow are presented in Figures $4 \& 5$. The new drag coefficient model performed well with the experimental data by the high values of the RSQ correlation coefficient, which were $98 \%$ \& 99\% respectively, see Figures 6 and 7 .

When the viscosity is relatively high, such as in single phase oil flow, the regime is usually laminar and the Reynolds number tends to be very small, see Figure 8 . The particle in this case experiences a higher drag coefficient and low particle settling rate. The flowing fluid properties around the solid particle are an important factor in determining the drag coefficient [10]. The RSQ correlation coefficient was $99 \%$, see Figure 7.

Independent $C_{D}-R_{e}$ data [16] from literature was used to validate the model, see Figure 9. There was excellent agreement between the experimental data and model prediction including published data. The RSQ correlation coefficient was $97 \%$.

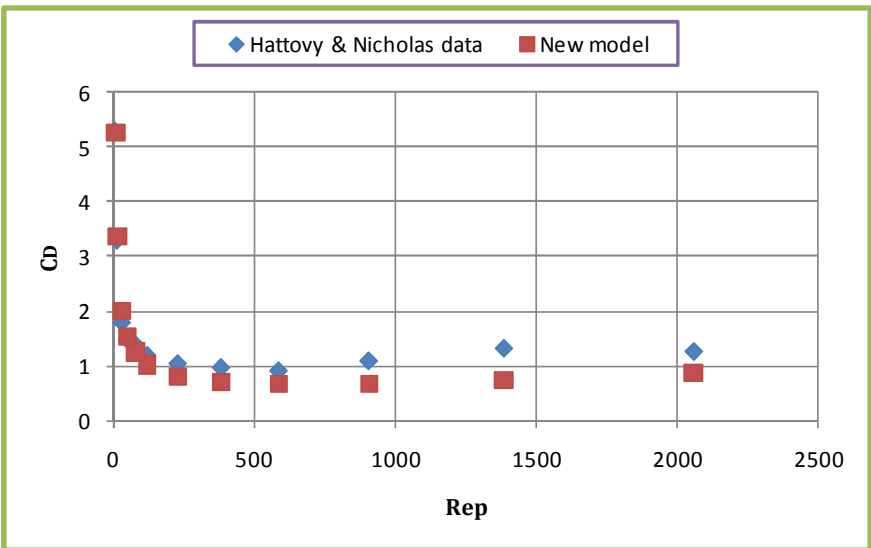

Figure 9: New $C_{D}$ model prediction with literature data

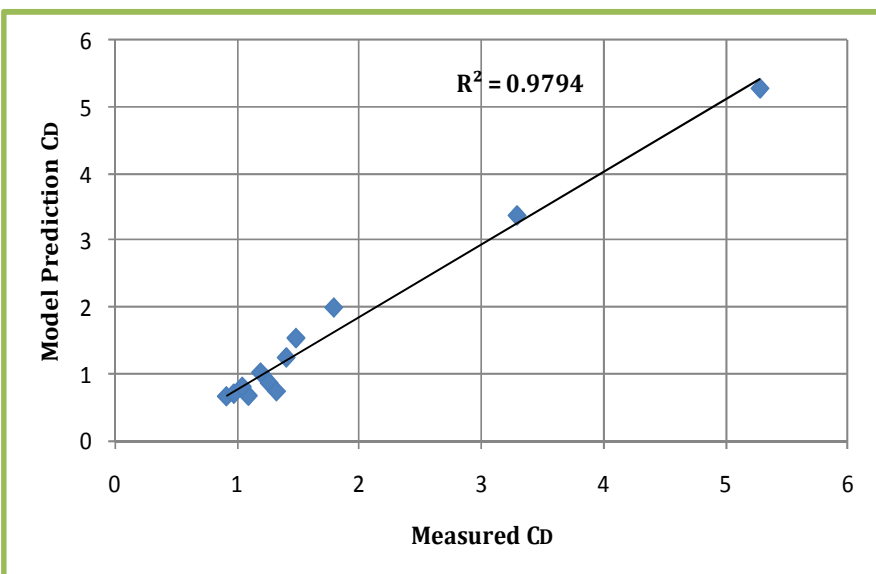

Figure 11: Comparison of measured and model prediction $C_{D}$ for single-phase water flow

The new model was equally compared with selected drag coefficients from the literature, as shown in Figure 10, giving better correlation with experimental data. In general, comparison of the experimental results and that of the $C_{D}$ model predictions are found to be largely in agreement. Table 2 shows the statistical parameter between the two measured drag coefficients and drag coefficient predicted with the new model.

Table 2: Statistical Parameters for the Drag Coefficient Model

\begin{tabular}{|l|l|l|l|l|}
\hline & \multicolumn{3}{|c|}{ Drag Coefficient Model Predictions } \\
\hline Error margin & $\begin{array}{l}\text { Single- } \\
\text { phase } \\
\text { oil }\end{array}$ & $\begin{array}{l}\text { Single- } \\
\text { phase } \\
\text { water }\end{array}$ & $\begin{array}{l}\text { Two- } \\
\text { phase } \\
\text { oil- } \\
\text { water }\end{array}$ & $\begin{array}{l}\text { Three- } \\
\text { phase } \\
\text { water- } \\
\text { oil-air }\end{array}$ \\
\hline $\begin{array}{l}\text { Average } \\
\text { percentage } \\
\text { error (APE) }\end{array}$ & 13.81 & 16.30 & 10.86 & 1.71 \\
\hline $\begin{array}{l}\text { R-Square } \\
\left.\text { value (R }{ }^{2}\right)\end{array}$ & 0.9996 & 0.9794 & 0.9996 & 0.9869 \\
\hline
\end{tabular}

\section{CONCLUSIONS}

We investigated drag coefficients for oil and gas multiphase systems. Analysis clearly showed that 
single-phase models are inadequate for multiphase flow prediction, and also, merely extending $C_{D}$ models used in hydraulic transport is quite misleading. The developed model in this work, has effectively addressed these concerns. It has been shown to adequately predict for both single-phase and multiphase flow when compared with experimental data. This is evident in the results presented. This new model effectively accounts for the complexities associated with multiphase flow in pipes, and has the potential to solve the problem of sand depositions, and thus, minimizing flow assurance challenges in multiphase flow.

\section{REFERENCES}

1. GOVIER, G.W. AND AZIZ, K., 1972. The Flow of Complex Mixtures in Pipes. 4th ed. Malabar Florida: Robert E. Krieger Publishing Company.

2. LIU, H., 2003. Pipeline Engineering. Lewis Publisher, A CRC Press Company.

3. LOTH, E., 2008. Drag of non-spherical solid particles of regular and irregular shape. Powder Technology, 182, pp. 342-353

4. DOAN, Q. AND GEORGE, A.E., 1998. Flow of Oil and Sand in a Horizontal Well. Journal of Petroleum Technology, 37(10), pp. 39-45

5. TRAN-CONG, S., GAY, M. AND MICHAELIDES, E.E., 2004. Drag coefficients of irregularly shaped particles. Powder Technology, 139, pp. 21-32

6. CHENG, N., 2009. Comparison of formulas for drag coefficient and settling velocity of spherical particles. Powder Technology, 189, pp. 395-398

7. STEVENSON, P. et al., 2001. The Transport of Particles at Low Loading in Near-Horizontal Pipes by Intermittent Flow. Chemical Engineering Science, 56, pp. 2149-2159

8. LASKOVSKI, D., STEVENSON, P. AND GALVIN, K.P., 2009. Lift and drag forces on an isolated cubic particle in pipe flow. Chemical Engineering Research and Design, 87, pp. 1573-1581

9. DANIELSON, T.J., 2007. Sand Transport Modeling in Multiphase Pipelines. Offshore Technology Conference. May. Houston, USA: SPE

10. ALMEDEIJ, J., 2008. Drag coefficient of flow around a sphere: Matching asymptotically the wide trend. Powder Technology, 186, pp. 218-223

11. ZASTAWNY, M., MALLOUPPAS, G., ZHAO, F. AND WACHEM, B., 2012. Derivation of drag and lift force and torque coefficients for non-spherical particles in flows. International Journal of Multiphase Flow, 39, pp. 227-239

12. CARMICHAEL, G.R., 1982. Estimation of the Drag Coefficient of Regularly Shaped Particles in Slow Flows from Morphological Descriptors. American Chemical Society, 21, pp. 401-403

13. CHIEN, S., 1994. Settling Velocity of Irregularly Shaped Particles. SPE Drilling and Completion, , pp. 281-289

14. LOTH, E., 2008. Drag of non-spherical solid particles of regular and irregular shape. Powder Technology, 182, pp. 342-353

15. TURTON, R. , LEVENSPIEL, O. A short note on the drag correlation of spheres, Powder Technology. 47 (1986) 83-86

16. HOTTOVY, J.D. AND SYVESTER, N.D., 1979. Drag Coefficients for Irregularly Shaped Particles. American Chemical Society, 18(3), pp. 433-436

\section{Nomenclature}

CFD - Computational Fluid Dynamics

$C_{D}$ - Drag co-efficient

$R_{e}$ - Reynolds number

$R_{e p}$ - Particle Reynolds number 